\section{Pictures and Signals}

\section{P.W. Hawkes}

Signal Processing. Editor M. Kunt. 6/yr. (North-Holland.) Df1.220. IEEE Transactions on Pattern Analysis and Machine Intelligence. Editor T. Pavlidis. 6/yr. (IEEE Computer Society, Silver Springs, Maryland.) \$58 US, \$64 elsewhere.

SIGNAL processing is a very old subject, which has generated an extensive literature of books on signal theory and detection, stochastic processes, filtering and processing techniques, with time as the independent variable. Most of this is by, and addressed to electrical engineers, with contributions from pure mathematicians. In the past few years, the field has abruptly widened, with rapidly increasing interest in two (and higher) dimensional signals and in the application of processing methods to subjects that are not primarily the province of electrical engineers.

It is to a mixed audience that these two new journals, Signal Processing (SP) and the IEEE Transactions on Pattern Analysis and Machine Intelligence (PAMI), are addressed. Both contain papers, short communications or letters, and book reviews (PAMI) or "alerts" (SP). Both are attracting much the same kind of paper, though SP includes material that would probably have been sent to another of the IEEE Transactions series - a recent discussion of the "design of high order minimum phase FIR digital or CCD filters" is an example of this. SP also contains a sprinkling of papers on onedimensional signals, which rarely occur in PAMI.

PAMI has published many interesting papers in the field of image processing and pattern analysis since its first appearance in 1979 - on Hough and Radon transforms, on the use of moments, on the use of variable knot bicubic splines for image approximation, on mosaic models for textures, on the use of fuzzy set decomposition to assess clustering performance: these give a fair idea of the flavour of the contents. By contrast, SP is often more down-to-earth: recent papers have covered speech analysis by pole-zero decomposition of short-time spectra, a set of optimal discrete linear smoothers, a graphical system for geographical data processing and medical scintigraphic images.

\section{(4) IER tRANSACTIONS ON \\ PATTERN ANALYSIS AND MACHINE INTELLIGENCE}

Are these two new journals needed? Probably not, for the longer-established Computer Graphics and Image Processing has quite as distinguished an editor and editorial board as either of them, and would have been a suitable home for many of the papers in SP and most of those in
PAMI. Moreover, there are already IEEE Transactions on closely related topics (series $C, C O M$ and $A S S P$ in particular), and also such specialized titles as Pattern Recognition and Photogrammetria. Nevertheless, these newcomers cater for a rapidly expanding field and anyone working in it will have to have access to PAMI and probably to SP as well.

P.W. Hawkes is Maître de Recherches at the Laboratoire d'Optique Electronique, Toulouse.

\section{Solar Energy Foci}

\section{J.I.B. Wilson}

Solar Energy Materials. General editor B.O. Seraphin. 6/yr in 2 vols. (NorthHolland.) DG 360. Solar Cells. Editors-inchief T.J. Coutts et al. $8 / \mathrm{yr}$ in 2 vols. (Elsevier Sequoia.) SwFr. 380.

THE enthusiasm for "self-sufficiency" and "alternative energy" has generated an abundance of pamphlets and books, as well as many (often short-lived) magazines, but the official journal of the International Solar Energy Society, Solar Energy, has remained until recently the only place for the dissemination of most scientific and technical developments. Consequently, much useful information has only been available in obscure house journals, or has been published in such places as the many electronics journals. It has been especially difficult to keep up with progress in photovoltaic and photochemical technology without attending the overlarge international conferences, and papers which combined economics with natural sciences have not been easy to place.

Now two specialist journals have arrived to service the field, which is becoming divided into photochemical and photothermal conversion - Solar Energy Materials (SEM) - and photovoltaic conversion - Solar Cells (SC) - whilst Solar Energy itself has evolved into a mechanical engineering and systems forum. Although both of the new publications have a similar format, style and issue size, there are differences in cost and in the type of article which appears. The delay between acceptance and appearance is around six months in both, although some papers in SEM are undated.

In addition to technology, SC contains many theoretical analyses of solar cells as energy converters, as well as some interesting economic evaluations which are, after all, the final test of success of any new energy source. In contrast, SEM has been concerned mainly with the "recipe" type of paper, such as the preparation of selective coatings for thermal collectors. The combination of photothermal conversion, which is already economically viable (unlike solar cells), and photochemical

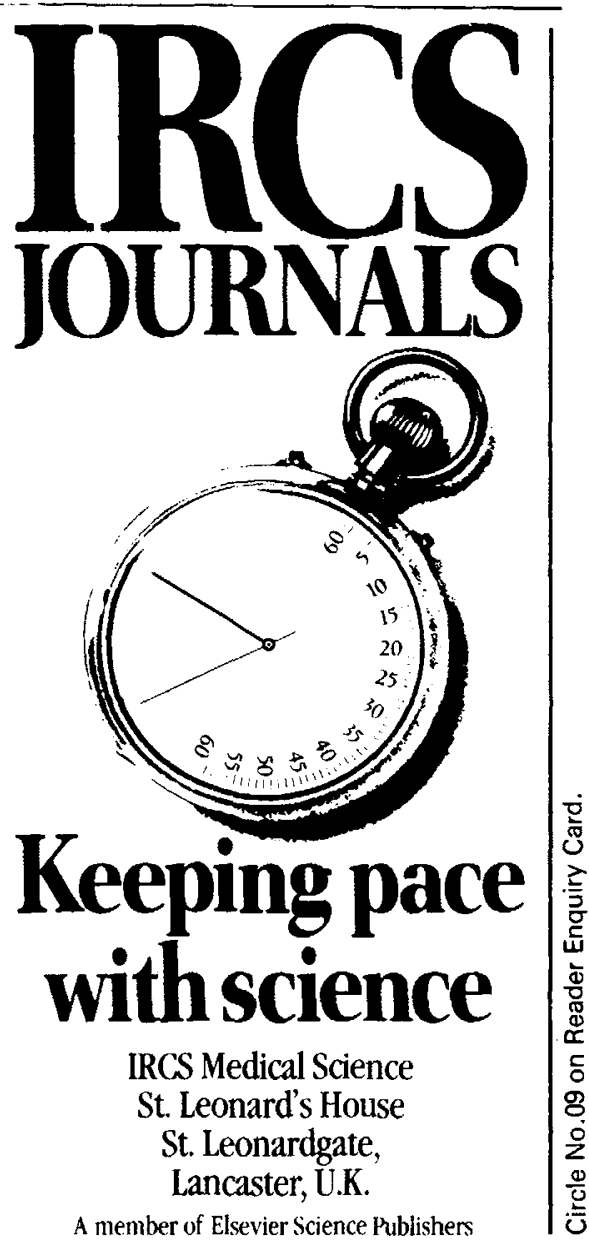

conversion, which is still a long way from the efficiency and operating lifetime required, may be an uneasy one, but neither of them uses the sophisticated materials preparation required by most solid-state devices. However, because of the similarity of operation of the nonthermal "quantum converters", I believe it is the intention of the editors of SC to relax the usual narrow sense of solar cell, meaning photovoltaic cell, to include, for instance, photoelectrochemical cells.

A useful feature of both journals is their publication of review papers, and the coverage of otherwise unreported workshops. Fifty per cent of the papers in each are from the USA, and another 30 per cent from Australia (reflecting the effort there into thermal collectors for high temperatures), otherwise the contributors are spread worldwide. Many papers are appearing in these new periodicals at the expense of established publications, but undoubtedly more new papers reach their intended audience.

The fortuitous separation of solar energy coverage into three or so divisions should assist librarians and individuals in their choice of subscription, but all three of the journals referred to are essential for any serious solar energy programme.

J.I.B. Wilson is Senior Research Fellow in the Physics Department, Heriot-Watt University, Edinburgh. 